\title{
Monitoring marine plankton ecosystems. I: Description of an ecosystem approach based on plankton indicators
}

\author{
Grégory Beaugrand* \\ CNRS, UMR 8013 ELICO, Université de Lille 1, 28 avenue Foch, BP 80, 62930 Wimereux, France
}

\begin{abstract}
A procedure is presented that allows monitoring of the dynamic regime of pelagic ecosystems in the North Atlantic Ocean. It uses a diversity index (mean number of species per continuous plankton recorder [CPR] sample) and species assemblage indicators calculated from all calanoid copepods (108 species) identified by the CPR survey since 1958. In any region of the North Atlantic covered by the CPR survey, the procedure calculates the values of these ecosystem indicators using a constant number of samples, selected randomly, and checks any bias associated with the spatial and temporal heterogeneity of the sampling. The procedure is described and illustrated in this study using CPR data in the central North Sea. The usefulness of this tool is demonstrated by a study of the sensitivity of the indicators to the number of CPR samples employed in the estimation of monthly or annual means. Firstly, it is shown that on an annual scale the procedure improves the quality of estimations. However, when long-term changes of a plankton indicator are examined for a particular month, it is crucial to use an appropriate number of CPR samples to detect a significant link between the biological and hydro-climatic environment. Secondly, the importance of using species assemblage indicators is demonstrated. They allowed the detection and the ecological interpretation of both episodic events and the regime shift in the central North Sea. It is shown that the regime shift in the North Sea had a strong impact on plankton community structure and was marked by an increase in diversity related to a progressive increase in warm-water species and a decrease in cold-water species. This study also has important implications for researchers using the CPR data. It demonstrates the robustness of the CPR data, but on the other hand also shows that the spatial and temporal heterogeneity should be assessed with care before interpreting the long-term changes of a CPR-derived plankton indicator.
\end{abstract}

KEY WORDS: Plankton · Monitoring · Pelagic ecosystems · Continuous plankton recorder survey Resale or republication not permitted without written consent of the publisher

\section{INTRODUCTION}

The biodiversity of marine ecosystems is being altered by many human-induced factors, including overexploitation of marine resources (e.g. Omori et al. 1994, Lindeboom 1995, Botsford et al. 1997, Jennings \& Kaiser 1998), chemical pollution and physical alterations (Norse 1993), eutrophication (North Sea Task Force 1993), invasion of exotic species (Carlton \& Geller 1993, Steneck 1998, Edwards et al. 2001) and global warming (Hughes 2000, Beaugrand et al. 2002a). With this multitude of direct and indirect anthropogenic influences, in addition to the confounding effects of the natural variability of the marine environment related to hydro-climatic forcing (e.g. Fromentin \& Planque 1996, Beaugrand et al. 2000a, Reid \& Beaugrand 2002), managing marine ecosystems and achieving sustainable exploitation represents a real challenge. To detect, understand and anticipate modifications in pelagic ecosystems induced by global change, a large-scale monitoring system is needed. 
The continuous plankton recorder (CPR) survey is the largest plankton monitoring programme in the world. To date, ca. 180000 CPR samples have been collected. It has been used to answer many ecological questions, ranging from biogeography to issues related to climate change. However, the problem of representativeness of CPR samples has been rarely addressed or taken into consideration in analyses (however, see Hays et al. 1993, Beaugrand et al. 2000b, Beaugrand et al. 2001, Beaugrand \& Edwards 2001). Many studies have used the standard CPR areas (see Colebrook 1984, his Fig. 1). Although used effectively in past studies, the use of the standard CPR areas has a number of drawbacks. As the size of the standard areas is fixed, the system cannot deal with specific areas of concern. But more importantly, both the temporal and spatial heterogeneity of sampling within an area is not consistent.

This study presents a new way of monitoring the dynamic regime (or state equilibrium, as defined by Scheffer et al. 2001) of North Atlantic pelagic ecosystems, with particular emphasis on its utility to evaluate climate change-induced modifications in marine plankton ecosystems based on data from the CPR survey. The procedure can be used in any region of the North Atlantic covered by the CPR survey, but is evaluated in the present study in the North Sea, the region most monitored by the CPR survey. The method presented uses the following: (1) A numerical procedure called Copepod Indicator Monitoring Toolbox System (CIMOTS). This programme allows the examination of long-term changes of ecosystem indicators (i.e. calanoid copepod species assemblages and a diversity index) in any region of the North Atlantic Ocean covered by the CPR survey. It is based on a new way to construct time series from the CPR survey to produce time series minimising the effect of the spatial and temporal heterogeneity of the CPR sampling. (2) An ecosystem approach (Frontier \& Pichot-Viale 1993), which considers the community structure of calanoid copepods. The procedure utilises a new type of ecosystem indicators, based on species assemblages (Beaugrand et al. 2002b), recently used by Beaugrand et al. (2002a), and a diversity index (i.e. the mean number of calanoid copepod species per CPR sample).

The necessity and usefulness of this procedure is demonstrated studying the sensitivity of the ecosystem indicators to the number of CPR samples in the North Sea. The method evaluates the influence of the spatial and temporal fluctuations in the CPR sampling on measures of calanoid copepod assemblage and calanoid copepod diversity (as the mean number of species per CPR sample, see Beaugrand et al. 2002a,b). Examples from the central North Sea are then given to show the interest of the procedure to monitor responses of pelagic ecosystems to hydro-meteorological forcing.

\section{MATERIALS AND METHODS}

Plankton and physical data. Biological data used in this study have been collected by the continuous plankton recorder (CPR) survey. This programme has monitored the presence or abundance of more than 400 plankton species, taxa, or groups on a monthly basis over the North Atlantic since 1946 (Warner \& Hays 1994). Samples are collected by a high-speed plankton recorder towed behind ships of opportunity at a standard depth of approximately $6.5 \mathrm{~m}$ (Hays 1994). Inside the sampler, plankton is retained by a continuously moving band of silk with an average mesh size of $270 \mu \mathrm{m}$. Then, a second band of silk covers the organisms to form a sandwich that is reeled into a tank containing $4 \%$ formaldehyde. On return to the laboratory, the silk is unwound and cut into sections corresponding to $18.5 \mathrm{~km}$ of tow. Each section of silk is a CPR sample and corresponds to about $3 \mathrm{~m}^{3}$ of filtered seawater (Hays 1994). Alternate samples are analysed under a microscope and the organisms are identified and counted (Warner \& Hays 1994). For counting zooplankton, a category system, close to a logarithmic scale of abundance, is used to reduce analysis time (Warner \& Hays 1994). More detailed information about the CPR survey can be found in Colebrook (1960, 1975), and Warner \& Hays (1994). Data for the period 1958 to 1999, corresponding to ca. 170000 samples, were considered in this study.

ICES temperature data in the central North Sea (period 1958 to 1999) were provided by Keith Brander (ICES, Copenhagen).

Use of species assemblages as ecosystem indicators. Beaugrand et al. (2002b) have recently divided the diversity of calanoid copepod (108 species or taxa), one of the best taxonomic groups sampled by the CPR survey, into species assemblages. This classification was based on the whole of regions of the North Atlantic covered by the CPR survey. This separation was done utilising geostatistics and multivariate analyses, in combination with the method of 'indicator values' designed by Dufrêne \& Legendre (1997). At the scale of the North Atlantic basin and at a resolution allowing the detection of spatial features of ca. $200 \mathrm{~km}$ (mesoscale) resolution, 9 calanoid copepod assemblages were identified. Three criteria were used: (1) spatial distribution of species, (2) similarity in the seasonal variability of species and (3) their diel variations. The 9 calanoid copepod species assemblages were closely related to a stable-biotope component (i.e. a component geographically stable, such as topography; van der Spoel 1994) or a substrate-biotope component (i.e. a component depending on the water mass, such as oceanic current; van der Spoel 1994). Following Beaugrand et al. (2002a), it is proposed to use the mean 
number of species per CPR sample belonging to each species assemblage as an ecosystem indicator to monitor modifications in the structural organisation of North Atlantic plankton ecosystems. A description of the 7 species assemblages that are likely to be found in the North Sea is given in Table 1. The warm-temperate pseudo-oceanic species assemblage (A1) and coastal species assemblage (A3) will not be examined in this paper because they are not usually present in the region investigated in this study (central part of the North Sea).

Description of the 'Copepod Indicator Monitoring Toolbox System' (CIMOTS). CIMOTS uses the ecosystem indicators proposed by Beaugrand et al. (2002a). The programme utilises data collected by the CPR survey and therefore encompasses an area corresponding to the North Atlantic Ocean and its adjacent seas. It gives the long-term changes of all calanoid copepod species assemblages and the total number of calanoids per CPR sample (as a measure of total diversity index), ensuring that their long-term changes are not influenced by the spatial and temporal heterogeneity of the CPR sampling. Inside a spatial domain defined by the user, the procedure generates time series of both the mean number of species for each calanoid assemblage (see Table 1) and the mean number of calanoid copepod species per CPR sample (as a measure of total diversity). Each period of the time series is based on the same number of CPR samples, selected randomly among a pool of CPR samples. When, for a given period, the number of CPR samples available to calculate the ecosystem indicators is less than a userdefined threshold, no estimate is calculated and a missing datapoint is generated. In an area where the number of CPR samples is sufficiently high, this procedure allows the building of time series for each year (Option 1), each month or 2 mo period (Option 2) and for daylight/dark period (to adjust for the diel vertical migration of calanoid copepods) from 1958 to 1999. The numerical procedure comprises 3 steps (Fig. 1):

Step 1: The number of CPR samples available for each year, 2 mo periods and for both daylight and dark periods is examined (Fig. 1a, Option 2) within an area selected by 4 latitude and longitude coordinates (Fig. 1b, here the central North Sea). A complementary plot of the percentage of missing data in the time series as a function of the number of selected CPR samples is then produced (Fig. 1c). This diagram allows the selection of the number of samples used to produce the average value of all ecosystem indicators for each time period. The more samples used to calculate the mean value of the ecosystem indicators for each time period, the more missing data there are in the time series (see the horizontal dashed line in Fig.1a). Thus, there is a trade-off between the quality of the estimate and the number of missing data in the time series. This changes as a function of the selected spatial domain and should always be evaluated to optimise the quality of the estimate. The number of samples to be used is fixed by examination of Fig. 1a,c.

Table 1. Species-assemblage indicators and their ecological preferences. More information about the biological composition of each species assemblage indicator can be found in Beaugrand et al. (2002b)

\begin{tabular}{|c|c|c|c|}
\hline $\begin{array}{l}\text { Species } \\
\text { assemblage } \\
\text { number }\end{array}$ & $\begin{array}{l}\text { Species assemblage } \\
\text { indicator }\end{array}$ & Species composition & Ecological preference \\
\hline A1 & $\begin{array}{l}\text { Warm-temperate } \\
\text { pseudo-oceanic } \\
\text { species }\end{array}$ & $\begin{array}{c}\text { Euchaeta gracilis, Euchaeta hebes, } \\
\text { Ctenocalanus vanus, Calanoides carinatus }\end{array}$ & $\begin{array}{l}\text { Warm water south of about } 50^{\circ} \mathrm{N} \\
\text { along the European shelf edge }\end{array}$ \\
\hline $\mathrm{A} 2$ & $\begin{array}{l}\text { Temperate pseudo- } \\
\text { oceanic species }\end{array}$ & $\begin{array}{c}\text { Rhincalanus nasutus, Eucalanus crassus, } \\
\text { Centropages typicus, Candacia armata, } \\
\text { Calanus helgolandicus }\end{array}$ & $\begin{array}{l}\text { Oceanic and neritic water, } \\
\text { especially along shelf edges } \\
\text { north to ca. } 55^{\circ} \mathrm{N}\end{array}$ \\
\hline A3 & Coastal species & $\begin{array}{c}\text { Isias clavipes, Anomalocera patersoni, } \\
\text { Labidocera wollastoni }\end{array}$ & Shallow and coastal habitat \\
\hline A4 & Shelf-sea species & $\begin{array}{c}\text { Centropages hamatus, Temora longicornis, } \\
\text { Pseudocalanus adult, Para-Pseudocalanus spp. }\end{array}$ & Neritic distribution \\
\hline A5 & $\begin{array}{l}\text { Cold-temperate } \\
\text { species }\end{array}$ & $\begin{array}{c}\text { Aetideus armatus, Pleuromamma robusta, } \\
\text { Acartia spp., Metridia lucens }\end{array}$ & $\begin{array}{l}\text { Mixed-water usually found at } \\
\text { the boundary between warm } \\
\text { and subarctic water } \\
\text { (e.g. Oceanic Polar Front) }\end{array}$ \\
\hline A6 & Subarctic species & $\begin{array}{c}\text { Heterorhabdus norvegicus, } \\
\text { Scolecithricella spp., Euchaeta norvegica, } \\
\text { Calanus finmarchicus }\end{array}$ & Subarctic water \\
\hline A7 & Arctic species & $\begin{array}{c}\text { Calanus hyperboreus, Metridia longa, } \\
\text { Calanus glacialis }\end{array}$ & Arctic water \\
\hline
\end{tabular}



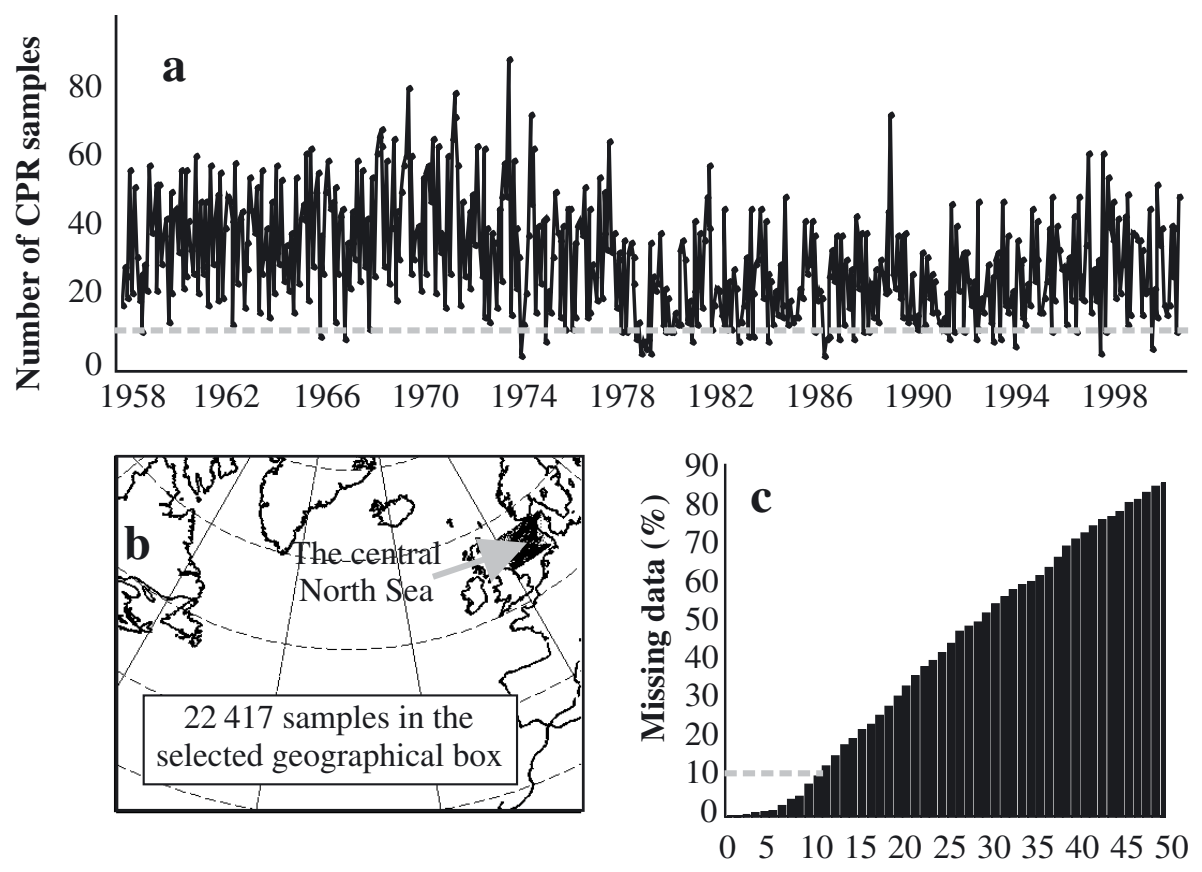

Step 1: Examination of the number of continuous plankton recorder (CPR) samples (see a) within a selected area (geographical box in b) and production of a plot of missing data in the time series as a function of selected CPR samples (c)

Selected number of CPR samples

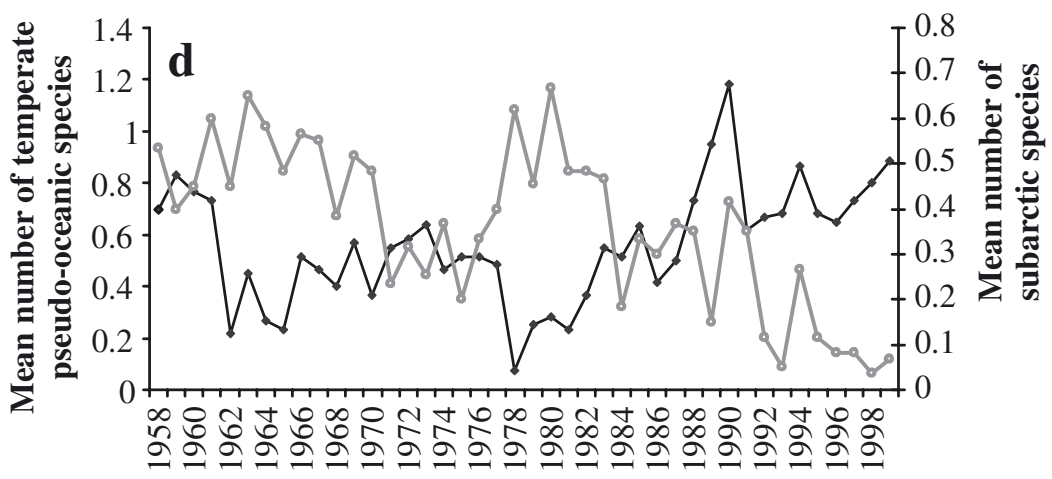

Step 2: The programme (CIMOTS: copepod indicator monitoring toolbox system) builds the time series by randomly selecting a number of CPR samples for each time interval in the selected area. The annual mean of all ecosystem indicators (e.g. species assemblages, such as temperate pseudooceanic species) is calculated (d)

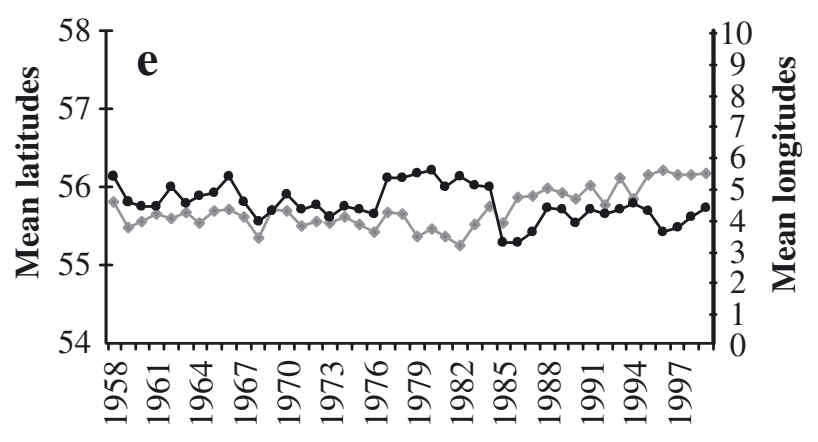

Step 3: Long-term changes in the average location of the CPR sampling in the selected area (e) are checked. When significantly correlated with ecosystem indicators (see d), the procedure is restarted using a more restricted region

Fig. 1. Summary of procedures used to build a time-series of the ecosystem indicators used in this study (Steps 1,2 and 3 ). (a) Number of continuous plankton recorder (CPR) samples available in the selected region for each year, 2-mo period and daylight/dark period. Dashed grey line represents 10 CPR samples. Arrow in panel b shows the location of the 22417 CPR samples in the selected spatial window. Panel c indicates the number of periods for which no value is calculated because the number of samples available is below the selected threshold. For example, if one chooses $10 \mathrm{CPR}$ samples (- =- =- in a,c) to calculate the mean number of pseudo-oceanic species for each time period, there will be ca. $10 \%$ missing data. This plot helps to select the optimum number of samples to be used in the annual mean of species assemblage indicators. (d) Annual mean of ecosystem indicators: temperate pseudo-oceanic species assemblage $(\bullet)$, subarctic species assemblage $(\bullet \longrightarrow)$. No correlation between the average location (latitude: $\bullet$; longitude: $\bullet$ ) of the CPR sampling (e) and the ecosystem indicators used in d was significant 
Step 2: The programme builds the time series by randomly selecting the specified number of CPR samples for each time interval in the selected spatial domain. If there is not enough data within a given time period (i.e. 1974 for January-February during daylight), a missing data point is generated. Then, the annual mean of all ecosystem indicators (species assemblages and total diversity) can be calculated. If the number of missing data for a given year is too high (e.g. estimates are missing for several months), no annual mean is displayed. Again, a trade-off exists between the number of missing data and the quality of the annual estimation. The threshold is fixed by trial and error. Fig. 1d presents an example of output produced by the procedure CIMOTS. The example shows the long-term changes in the mean number of both temperate pseudooceanic (i.e. species that occur in both oceanic and neritic waters but have their main centre of distribution above the shelf-edge) species and subarctic species. These 2 species assemblages are significantly negatively correlated $(\mathrm{r}=-0.59, \mathrm{p}<0.05, \mathrm{n}=42)$ in the selected region (central North Sea).

Step 3: This stage checks the average spatial location of the sampling in the area. If the area selected is too large or/and located near a biogeographical boundary, a trend in the abundance of one species or diversity may sometimes be explained by a change in the average sampling location (latitude or longitude) as the CPR survey used commercial routes. To verify this point (Fig. 1e), correlations are calculated between the times series of mean (annual or monthly mean) latitude, longitude and the mean values (annual or monthly mean) of the ecosystem indicators. If a significant link is detected, the procedure is restarted using a more restricted region. No significant correlation was found between the ecosystem indicators (Fig. 1d) and either the mean latitude and longitude of sampling (Fig. 1e). The selection of the spatial domain is not easy. It should be, as far as possible, the smallest possible, because in too big an area the species composition might change. At this stage, knowledge of the biogeography of the species assemblages is needed (e.g. Beaugrand et al. 2002b). A trade-off also exists between the size of the selected area and the number of samples. In the North Sea, the high number of CPR samples nearly guarantees a good compromise, but in certain areas of the North Atlantic Ocean, poorly covered by the CPR survey (e.g. oceanic areas south of $50^{\circ} \mathrm{N}$ to the west of $20^{\circ} \mathrm{W}$ ), it might become more difficult to obtain a good estimation in ecologically homogeneous areas.

Sensitivity of the indicators to the number of CPR samples used in the procedure. To test the sensitivity of the ecosystem indicators to the number of CPR samples, the central North Sea $\left(54^{\circ} \mathrm{N}, 58^{\circ} \mathrm{N}, 0^{\circ} \mathrm{E}, 10^{\circ} \mathrm{E}\right.$,
Fig. 1b) was selected because of its high number of CPR samples (22417 samples) and the welldocumented long-term changes in plankton composition and abundance (Fromentin \& Planque 1996, Reid \& Hunt 1998, Edwards et al. 1999, Heath et al. 1999). The temperate pseudo-oceanic species assemblage (Table 1) was used, as it is relatively well represented in the central North Sea.

Long-term monthly time series of the mean number of temperate pseudo-oceanic species per CPR sample (period 1958 to 1999) were built based on an increasing number of samples (from 1 to 10 samples for each time period, thus, a total of 10 time series). For each level of CPR samples, samples were selected randomly among a pool of samples for each time period. To examine the variability of each estimate, the procedure was repeated twenty times (referred hereafter in the text as simulation) from 1 to $10 \mathrm{CPR}$ samples, giving a total of 10 different numbers of CPR samples $\times 20$ simulations $=200$ long-term monthly time series. The resulting $4 \mathrm{D}$ matrix $(42 \mathrm{yr} \times 12 \mathrm{mo} \times 1$ to $10 \mathrm{CPR}$ samples $\times 20$ simulations) is displayed in Fig. 2 .

Ideally, the mean number of warm-temperate pseudooceanic species per CPR sample based on 1 sample should be highly correlated (positively) with the mean number of warm-temperate species per CPR sample based on $10 \mathrm{CPR}$ samples. Furthermore, the mean number of warm-temperate pseudo-oceanic species per CPR sample should be highly correlated (positively) from 1 simulation to another. So, one should expect to have coefficients of correlation of 1 between estimations, a coefficient of determination of $100 \%$ and a probability of 0 if sampling by the CPR survey is perfect. The failure to totally meet those conditions can be considered as a measure of the imperfection of the CPR sampling.

Analysis 1: Correlations between the assessment of the mean number of temperate pseudo-oceanic species based on an increasing amount of CPR samples (from 1 to 9 samples) and that number based on 10 samples (considered as a reference estimate) were examined. The reference value of $10 \mathrm{CPR}$ samples was selected on the basis of results from a previous study (Beaugrand \& Edwards 2001). Beaugrand \& Edwards (2001, their Fig. 6A) showed that the species richness as assessed from 10 CPR samples was highly correlated with the (extrapolated) true species richness from all months in all parts of the North Atlantic Ocean. Furthermore, values superior to 10 would have increased steeply the number of missing data (see Fig. 1c).

Correlations were calculated considering the annual mean (average of all months) and for each month for the period 1958 to 1999. Correlation analysis was performed for each of the 20 simulations and then the average of the coefficients of correlation (determina- 


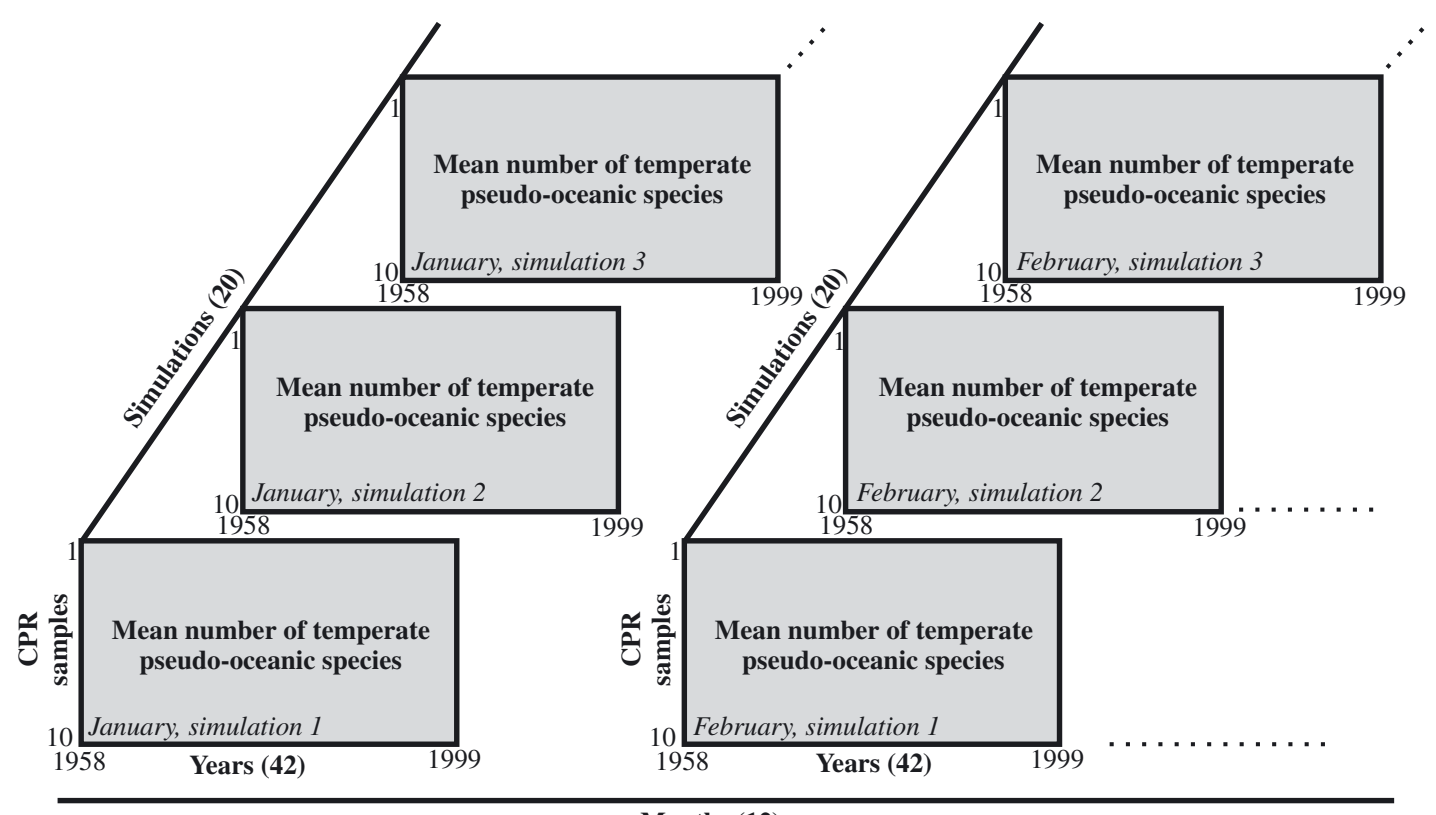

Months (12)

Fig. 2. Sensitivity of estimators to the number of continuous plankton recorder (CPR) samples used to calculate the average value of ecosystem indicators. Time series of the mean number of temperate pseudo-oceanic species were built for each month and using from 1 to $10 \mathrm{CPR}$ samples. The procedure was repeated 20 times in each case to estimate variability

tion and probability) was calculated. Coefficients of both correlation and determination, as well as the probability of the correlation, were examined to evaluate the accuracy of the CPR sampling and to see how to improve the quality of the assessments.

Analysis 2: In the first analysis, correlations should be interpreted with care, as data are not completely independent (i.e. a sample used to assess the value of the ecosystem indicator based on 1 CPR sample can also be used to assess the value of the ecosystem indicator based on $10 \mathrm{CPR}$ ). This limitation is stronger when the number of samples on which the mean number of species is based increases. If it is assumed that CPR samples are equally distributed along the time series (which is not the case, as shown by Fig. 1a), as there are 22417 for 504 time periods ( $12 \mathrm{mo} \times 42 \mathrm{yr}$ ), there are ca. 45 CPR samples available for each month. To overcome the limitation of the first analysis, correlations between monthly/annual values of the temperate pseudo-oceanic species assemblage based on an increasing number of CPR samples (from 1 to $10 \mathrm{CPR}$ samples) and monthly/annual sea surface temperature were also examined. Twenty simulations were also performed for each number of CPR samples. It was assumed that, on average, a linear relationship between the mean number of temperate pseudo-oceanic species and sea surface temperature exists. This has been recently shown for the same species assemblage in the North Sea by Beaugrand et al. (2002a) and for 2 of the 3 species that compose this species assemblage by Lindley \& Reid (2002). In that analysis, if sampling by the CPR was perfect, the correlation and probability should be identical when the assessment is performed from 1 to 10 CPR samples and whatever the simulation. The failure to meet those conditions can be considered as a measure of the accuracy of the CPR sampling.

For all correlation coefficients, the Box \& Jenkins (1976) autocorrelation function, modified by Chatfield (1996), was used to estimate the autocorrelation of all time series. When time series were significantly autocorrelated, the correction of the probability was applied utilising the Chelton (1984) formula as recommended by Pyper \& Peterman (1998).

\section{RESULTS}

\section{Analysis 1}

Fig. 3 shows that the correlation between the mean annual number of temperate pseudo-oceanic species with monthly estimates based on 1 CPR sample and the reference estimate (monthly estimations based on 10 CPR samples), was high. The mean Pearson correlation coefficient of the 20 simulations was $r_{m}=0.8$ and the mean probability $\mathrm{p}_{\mathrm{m}}$ was less than 0.0001 . When the monthly estimate was based on one CPR sample, $64 \%$ of the variation of the mean annual number of 


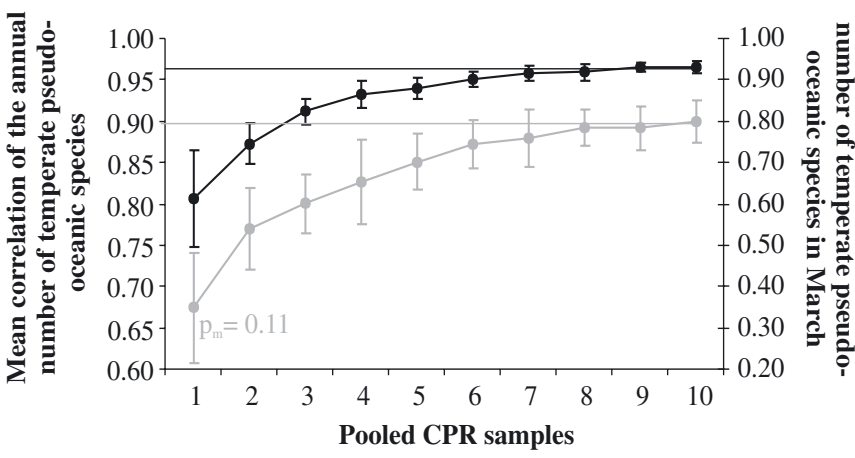

Fig. 3. Correlations (mean $\pm 1 \mathrm{SD} ; \mathrm{n}=20$ ) between the mean number of temperate pseudo-oceanic species $(\bullet \bullet$ : annual; $(\bullet$ in March) based on a pooled amount of continuous plankton recorder (CPR) samples (from 1 to 10) and that number based on 10 CPR samples in the central North Sea. The annual mean was calculated by averaging each monthly time-series based on a pooled number of CPR samples (1 to 10). All correlation coefficients were, on average, significant, with the exception of the correlation between the mean number of temperate species based on 1 CPR sample (mean probability $\mathrm{p}_{\mathrm{m}}=0.11$ )

temperate pseudo-oceanic species (reference value, monthly estimates based on 10 CPR samples) was explained. When the monthly estimate was based on 5 CPR samples, $88 \%$ of the variability of this ecosystem indicator (reference value, monthly estimations based on 10 CPR samples) was explained. This represents a subtantial increase of $24 \%$. A similar analysis was also performed for each month. For example, in March, correlation between the mean number of temperate pseudo-oceanic species based on 1 CPR sample and the reference estimate (10 CPR samples) was weak and not statistically significant on average (Fig. 3). The mean Pearson correlation coefficient of the 20 simulations was $\mathrm{r}_{\mathrm{m}}=0.35$ and the mean probability was $\mathrm{p}_{\mathrm{m}}=0.11$. When the assessment was based on $>1 \mathrm{CPR}$, correlation became significant for that month.

Table 2 presents detailed analyses performed for every month based on 1 and 5 CPR samples. Significant relationships between estimations based on $1 \mathrm{CPR}$ sample and the reference estimates (based on $10 \mathrm{CPR}$ samples) existed for 9 mo (on average for the 20 simulations). However, values of the standard deviation indicate that the relationship was high for only $3 \mathrm{mo}$ (August to October). On average, the value for the mean coefficient of determination was weak (between 12.17 and $28.53 \%$ ), explaining only a small percentage of the variability of the ecosystem indicator based on 10 CPR samples (between 19.06 and 39.70\%). Based on 5 CPR samples, all relationships became highly significant and explained, on average, between 40.3 and $61.6 \%$ of the total variability.

\section{Analysis 2}

The analysis above is limited by the fact that the more estimates are based on a large number of CPR samples, the less independent the observations are. For example, estimation based on $8 \mathrm{CPR}$ samples has a greater probability to have a common CPR sample with the reference estimation (based on $10 \mathrm{CPR}$ values) than estimation based on only $1 \mathrm{CPR}$ sample. Therefore, an empirical analysis was performed based on the relationship between temperate pseudooceanic species and sea surface temperature. Fig. 4a shows that a correlation was detected between the

Table 2. Relationships between the mean number of temperate pseudo-oceanic species based on 1 and 5 continuous plankton recorder (CPR) samples and the mean number of temperate pseudo-oceanic species based on 10 CPR samples (reference value) from January to December (period 1958 to 1999). Each parameter is the mean of 20 values, corresponding to 20 simulations. Values in parentheses are \pm SD or, for coefficient of determination, mean $\%$ of estimation of the coefficient of determination based on 10 CPR samples. Bold indicates probability $\geq 0.05$

\begin{tabular}{|c|c|c|c|c|c|c|}
\hline \multirow[b]{2}{*}{ Month } & \multicolumn{3}{|c|}{ Based on 1 CPR sample - } & \multicolumn{3}{|c|}{ Based on 5 CPR samples } \\
\hline & $\begin{array}{c}\text { Pearson } \\
\text { correlation } \\
\text { coefficient }\end{array}$ & $\begin{array}{c}\text { Coefficient of } \\
\text { determination }(\%)\end{array}$ & Probability & $\begin{array}{c}\text { Pearson correlation } \\
\text { coefficient }\end{array}$ & $\begin{array}{c}\text { Coefficient of } \\
\text { determination }(\%)\end{array}$ & $\begin{array}{l}\text { Probability } \\
\quad\left(\times 10^{-5}\right)\end{array}$ \\
\hline January & $0.41( \pm 0.16)$ & $16.46(25.21)$ & $0.07( \pm 0.17)$ & $0.71( \pm 0.11)$ & $50.20(76.89)$ & $50( \pm 157)$ \\
\hline February & $0.40( \pm 0.10)$ & $15.81(26.36)$ & $0.03( \pm 0.08)$ & $0.63( \pm 0.07)$ & $40.27(67.14)$ & $11( \pm 27)$ \\
\hline March & $0.35( \pm 0.13)$ & $12.17(19.06)$ & $0.11( \pm 0.22)$ & $0.70( \pm 0.07)$ & $49.27(77.20)$ & $1( \pm 3)$ \\
\hline April & $0.42( \pm 0.12)$ & $17.60(25.34)$ & $0.04( \pm 0.08)$ & $0.75( \pm 0.06)$ & $56.44(81.28)$ & $0( \pm 1)$ \\
\hline May & $0.39( \pm 0.13)$ & $15.43(25.57)$ & $0.05( \pm 0.10)$ & $0.65( \pm 0.09)$ & $42.39(70.25)$ & $48( \pm 189)$ \\
\hline June & $0.41( \pm 0.14)$ & $16.76(25.268)$ & $0.05( \pm 0.07)$ & $0.73( \pm 0.07)$ & $53.59(80.76)$ & $1( \pm 2)$ \\
\hline July & $0.47( \pm 0.11)$ & 22.35 (32.09) & $0.02( \pm 0.04)$ & $0.74( \pm 0.07)$ & $55.03(79.03)$ & $1( \pm 4)$ \\
\hline August & $0.52( \pm 0.11)$ & $26.63(35.91)$ & $0.01( \pm 0.01)$ & $0.78( \pm 0.07)$ & $60.22(81.21)$ & $0( \pm 0)$ \\
\hline September & $0.51( \pm 0.09)$ & $25.59(34.01)$ & $0.01( \pm 0.01)$ & $0.78( \pm 0.04)$ & $60.56(80.48)$ & $0( \pm 0)$ \\
\hline October & $0.53( \pm 0.11)$ & $28.53(39.70)$ & $0.00( \pm 0.01)$ & $0.77( \pm 0.04)$ & $59.48(82.77)$ & $0( \pm 0)$ \\
\hline November & $0.48( \pm 0.13)$ & $22.86(33.14)$ & $0.02( \pm 0.06)$ & $0.74( \pm 0.05)$ & $54.87(79.56)$ & $0( \pm 0)$ \\
\hline December & $0.42( \pm 0.15)$ & $17.81(25.81)$ & $\mathbf{0 . 0 7}( \pm 0.19)$ & $0.73( \pm 0.07)$ & $53.08(76.92)$ & $1( \pm 1)$ \\
\hline
\end{tabular}



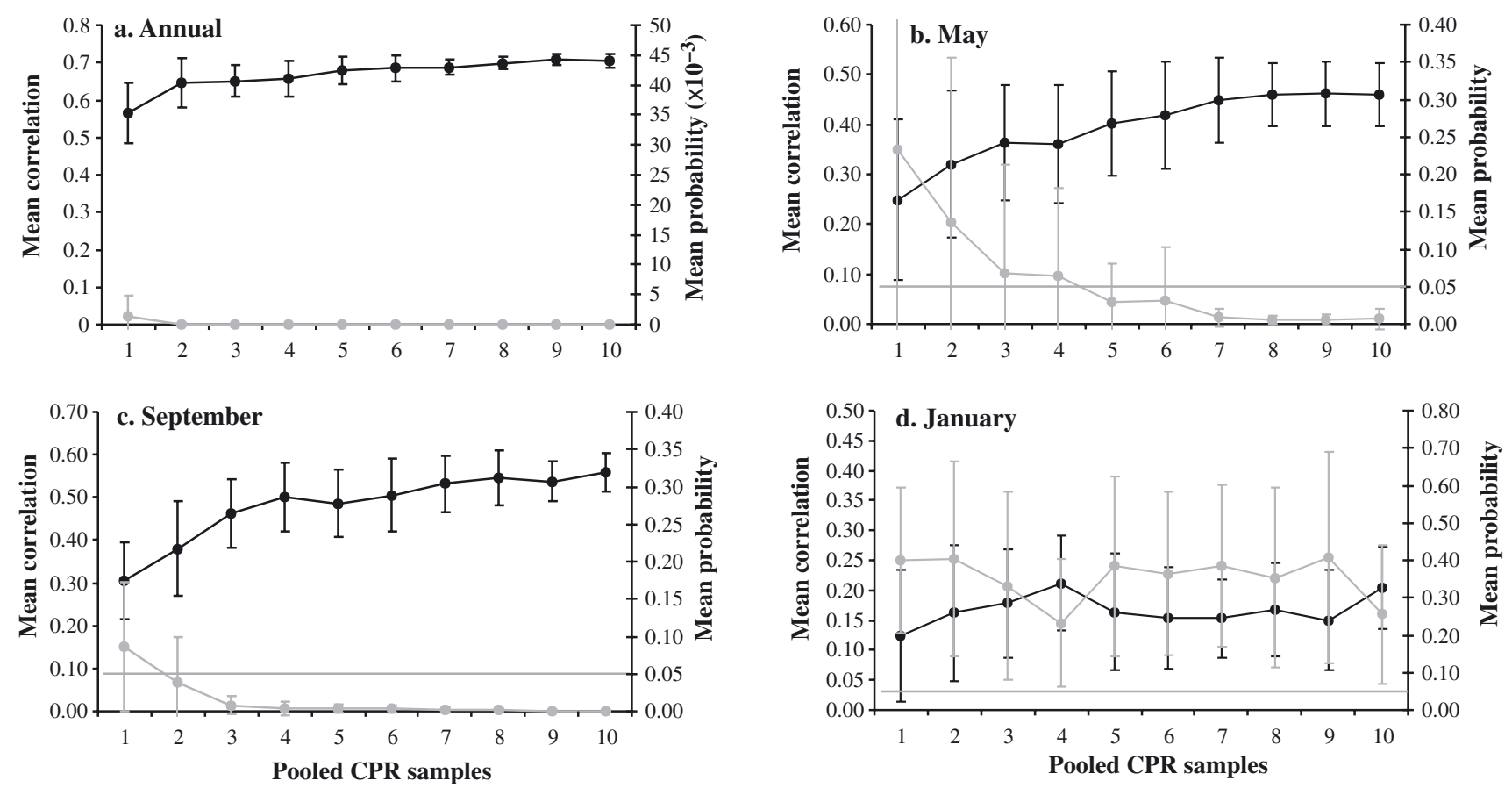

Fig. 4. Correlations (mean $\pm \mathrm{SD}, \mathrm{n}=20$; $\bullet$ ) between the mean number of temperate pseudo-oceanic species based on an increasing number of continuous plankton recorder (CPR) samples (between 1 and 10) and sea surface temperature (SST) in the central North Sea. Probabilities (mean $\pm \mathrm{SD}, \mathrm{n}=20 ; \bullet$ ) are also shown. (a) Correlation between the annual number of temperate pseudo-oceanic species and annual SST. Annual mean was calculated by averaging each monthly time series based on a pooled number of CPR samples (1 to 10). (b), (c) and (d) Correlation (and probability) between the mean number of temperate pseudooceanic species and SST in May, September and January, respectively. Horizontal lines indicate a probability of 0.05

annual mean number of temperate pseudo-oceanic species with monthly estimates based on 1 CPR sample and annual SST $\left(\mathrm{r}_{\mathrm{m}}=0.57, \mathrm{p}_{\mathrm{m}}<0.005\right)$. The coefficient of determination did not change much when CPR samples were added (from $32.1 \%$ for 1 , to $49.7 \%$ for 10 CPR samples).

On a monthly scale, results were different. For example in May (Fig. 4b), when less than 5 CPR samples were used, on average no significant correlations between the mean number of temperate pseudooceanic species and sea surface temperature were detected. From 5 samples, relationships between the number of temperate pseudo-oceanic species and SST were significant. Standard deviation of both the mean correlation and probability diminished when samples were pooled. In September (Fig. 4c), based on 1 sample, on average no significant correlation between the number of temperate pseudo-oceanic species and SST was detected. From 2 samples, correlations became significant. Here also, the standard deviation of both mean correlation and probability highly decreased with the number of pooled samples. The coefficient of determination increased from $9.3 \%$, on average, for 1 , to $31.2 \%$ for 10 CPR samples. In January, no correlation was detected, whatever the number of pooled samples (Fig. 4d). This result simply indicates the absence of correlation between these 2 variables for that month.

Table 3 summarises the results of the correlations calculated between monthly sea surface temperature and the monthly number of temperate pseudo-oceanic species based on 1 and 10 CPR samples. This analysis shows that even though a large number of significant correlations are detected ( 6 are on average less than or equal to a probability of 0.05 ) when only one sample is used, the standard deviation of the correlation, the probability, and the mean coefficient of determination all indicate strong noise in the data. When 10 samples are pooled, these same parameters show a deep reduction in the noise of the time series. Fig. 5 indicates that the mean correlation for each month with a significant correlation levelled off at ca. 7 CPR samples. When only 1 CPR sample was used, on average ca. $20 \%$ of the variability of sea surface temperature that is explained by the mean number of pseudo-oceanic species when 10 samples were used was assessed. When 5 samples were used, more than $80 \%$ of the variability of sea surface temperature (explained by the mean number of temperate pseudo-oceanic species when 10 samples were used) was estimated. 
Table 3. Relationships between the mean number of temperate pseudo-oceanic species based on 1 and 10 continuous plankton recorder (CPR) samples and monthly sea surface temperature from January to December (period 1958 to 1999). Each parameter is the average of 20 values, corresponding to 20 simulations. Values in parentheses are $\pm \mathrm{SD}$ or, for coefficient of determination, mean $\%$ of estimation of the coefficient of determination based on 10 CPR samples

\begin{tabular}{|c|c|c|c|c|c|c|}
\hline \multirow[b]{2}{*}{ Month } & \multicolumn{3}{|c|}{ Based on 1 CPR sample - } & \multicolumn{3}{|c|}{ Based on $10 \mathrm{CPR}$ samples } \\
\hline & $\begin{array}{l}\text { Pearson } \\
\text { correlation } \\
\text { coefficient }\end{array}$ & $\begin{array}{c}\text { Coefficient of } \\
\text { determination }(\%)\end{array}$ & Probability & $\begin{array}{c}\text { Pearson correlation } \\
\text { coefficient }\end{array}$ & $\begin{array}{c}\text { Mean } \\
\text { coefficient of } \\
\text { determination (\%) }\end{array}$ & Probability \\
\hline January & $0.12( \pm 0.11)$ & $1.55(37.26)$ & $0.38( \pm 0.20)$ & $0.20( \pm 0.07)$ & 4.16 & $0.26( \pm 0.19)$ \\
\hline February & $0.07( \pm 0.14)$ & $0.43(13.35)$ & $0.29( \pm 0.30)$ & $0.18( \pm 0.10)$ & 3.22 & $0.33( \pm 0.27)$ \\
\hline March & $0.04( \pm 0.15)$ & $0.17(15.59)$ & $0.50( \pm 0.25)$ & $0.10( \pm 0.09)$ & 1.09 & $0.51( \pm 0.27)$ \\
\hline April & $0.19( \pm 0.20)$ & 3.49 (21.52) & $0.04( \pm 0.32)$ & $0.40( \pm 0.06)$ & 16.22 & $0.01( \pm 0.02)$ \\
\hline May & $0.25( \pm 0.16)$ & $6.19(29.24)$ & $0.03( \pm 0.30)$ & $0.46( \pm 0.06)$ & 21.17 & $0.01( \pm 0.01)$ \\
\hline June & $0.19( \pm 0.13)$ & $3.59(24.55)$ & $0.10( \pm 0.30)$ & $0.38( \pm 0.05)$ & 14.62 & $0.02( \pm 0.02)$ \\
\hline July & $0.20( \pm 0.16)$ & $4.19(35.45)$ & $0.05( \pm 0.29)$ & $0.34( \pm 0.07)$ & 11.82 & $0.05( \pm 0.10)$ \\
\hline August & $0.16( \pm 0.11)$ & $2.72(29.47)$ & $0.17( \pm 0.28)$ & $0.30( \pm 0.07)$ & 9.23 & $0.08( \pm 0.09)$ \\
\hline September & $0.31( \pm 0.09)$ & $9.31(29.81)$ & $0.00( \pm 0.09)$ & $0.56( \pm 0.05)$ & 31.23 & $0.00( \pm 0.00)$ \\
\hline October & $0.10( \pm 0.12)$ & 1.09 (36.09) & $0.41( \pm 0.27)$ & $0.17( \pm 0.07)$ & 3.02 & $0.32( \pm 0.23)$ \\
\hline November & $0.19( \pm 0.11)$ & $3.63(19.47)$ & $0.03( \pm 0.25)$ & $0.43( \pm 0.06)$ & 18.64 & $0.01( \pm 0.01)$ \\
\hline December & $0.02( \pm 0.12)$ & $0.02(3.64)$ & $0.58( \pm 0.28)$ & $0.07( \pm 0.06)$ & 0.55 & $0.63( \pm 0.18)$ \\
\hline
\end{tabular}

\section{Long-term changes in calanoid copepod community structure in the central North Sea}

Fig. 6 shows long-term changes in both total diversity of calanoid copepods and species assemblage indicators and sea surface temperature in the central North Sea. Long-term changes in the mean number of temperate pseudo-oceanic species, shelf-sea species, cold-temperate mixed water species, and the total number of calanoid copepods were similar overall. These species assemblages, as well as the total diversity of calanoids, were related negatively to the mean number of subarctic species. When the mean number of subarctic species was, high the mean number of all other species was low, decreasing therefore the total number of calanoid copepod species. Table 4 summarises the relationships (correlation in the lower triangular part of the table and probability after correction to account for temporal autocorrelation in the upper triangular part) between each biological indicator and sea temperature in the central North Sea. Temperature covaries positively with the total diversity of calanoid copepods and the mean number of temperate pseudo-oceanic species. Temperature covaries negatively with the mean number of subarctic species.

Fig. 6 clearly identifies the impact of both the cold (ca. 1978 to 1982) and warm episodic events (1989 to 1991) described by Edwards et al. (2001) and (2002). During the cold episodic event, Fig. 6 reveals that there was a decrease in the total number of calanoid copepods related to a decrease in all species assemblages, with the exception of the mean number of subarctic species. During the warm episodic event, there was an increase in the total number of calanoids re- lated to an increase in the mean number of all species assemblages, with the exception of the shelf-sea species assemblage. Fig. 6 also shows the consequences of the regime shift (i.e. stepwise change in the dynamic regime of the North Sea ecosystems) revealed by Reid et al. (2001) in the central North Sea. However, the date of change is detected earlier than 1988 (date proposed by Reid et al. 2001), according to the total number of calanoid copepods, cold-temperate mixed water species and shelf-sea species.

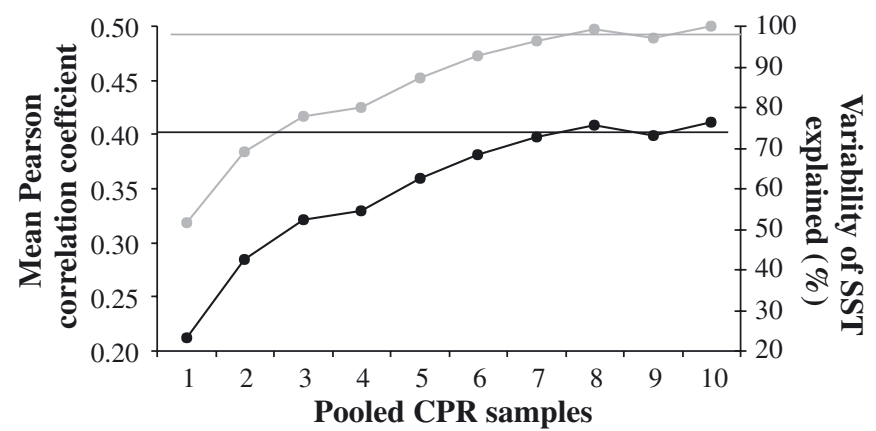

Fig. 5. Correlation between the mean number of temperate pseudo-oceanic species based on an increasing number of continuous plankton recorder samples (from 1 to 10) and sea surface temperature (SST) for all significant months $(\bullet \bullet$; see Table 3, April to September and November). The percentage of variability of SST explained by the mean number of pseudo-oceanic species, when between 1 and 10 samples were used, is also indicated $(\bullet \bullet)$. This was calculated by dividing each mean correlation, based on 1 to 10 samples, by the mean correlation when 10 samples were used and multiplying by 100 . The last value is therefore equal to $100 \%$. For example, the correlation between the mean number of temperate pseudo-oceanic species based on 1 CPR sample and SST only reaches ca. $55 \%$ of the value of the correlation between both variables when 10 samples are used 


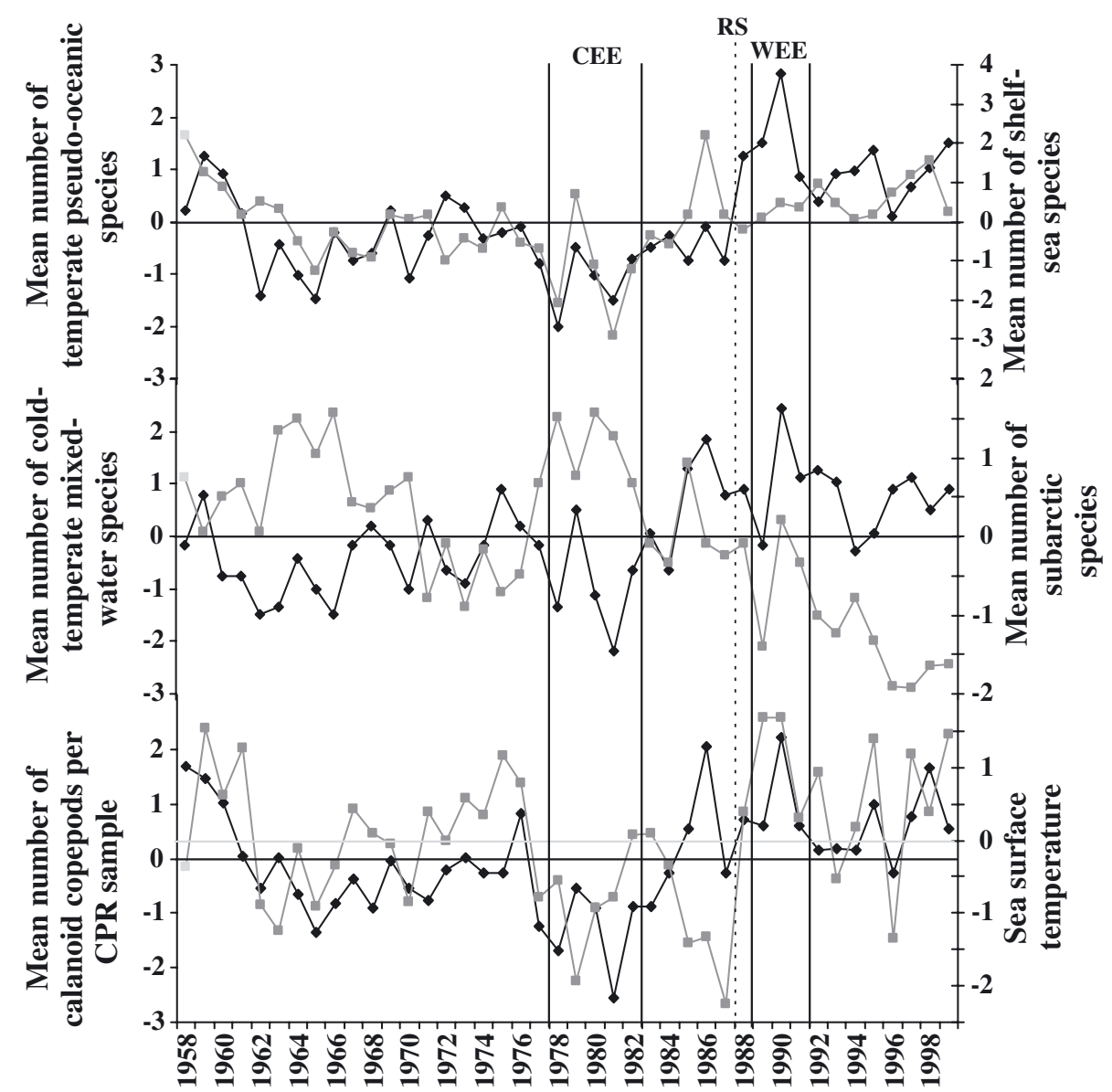

Fig. 6. Time series for all speciesassemblage indicators (annual mean) in the central North Sea based on the numerical procedure CIMOTS. Longterm changes (annual mean) in sea surface temperature are also indicated. CEE: cold-biological episodic event. WEE: warm-biological episodic event. RS: regime shift. CPR: continuous plankton recorder. Y-axes left and right correspond to $\longleftrightarrow$ and $\because$, respectively

\section{DISCUSSION}

\section{Sensitivity of ecosystem indicators to sampling size}

The problem of representativeness of CPR samples has been rarely addressed or taken into consideration. The presented procedure overcomes this problem by

Table 4. Correlations (lower triangular matrix) and probability after correction to account for temporal autocorrelation (upper triangular matrix) between all species assemblages and sea surface temperature in the central North Sea. TEM_S: sea surface temperature. TEM_B: sea bottom temperature. Assemblages A2 and A4 to A6 are defined fully in Table 1. A2: temperate pseudooceanic species; A4: Shelf sea species; A5: cold-temperate species; A6: subarctic species; D: total number of calanoid copepods per CPR sample. Bold values indicate significant correlation and probability $<0.05$

\begin{tabular}{|lrrrrrrr|}
\hline & \multicolumn{7}{c|}{ Central North Sea } \\
& A2 & A4 & A5 & A6 & D & TEM_S & TEM_B \\
\hline A2 & & $\mathbf{0 . 0 1 3 2}$ & $\mathbf{0 . 0 0 7 2}$ & $\mathbf{0 . 0 2 5 6}$ & $\mathbf{0 . 0 0 0 1}$ & $\mathbf{0 . 0 0 0 1}$ & $\mathbf{0 . 0 0 5 6}$ \\
A4 & $\mathbf{0 . 5 2}$ & & $\mathbf{0 . 0 0 2 2}$ & $\mathbf{0 . 0 7 2 0}$ & $\mathbf{0 . 0 0 0 0}$ & 0.4986 & 0.9439 \\
A5 & $\mathbf{0 . 5 8}$ & $\mathbf{0 . 5 9}$ & & $\mathbf{0 . 0 3 3 6}$ & $\mathbf{0 . 0 0 1 1}$ & 0.2022 & 0.2183 \\
A6 & $\mathbf{- 0 . 5 9}$ & $\mathbf{- 0 . 4 3}$ & $\mathbf{- 0 . 5 3}$ & & 0.0933 & $\mathbf{0 . 0 1 1 3}$ & 0.1121 \\
D & $\mathbf{0 . 7 7}$ & $\mathbf{0 . 8 0}$ & $\mathbf{0 . 6 5}$ & -0.43 & & $\mathbf{0 . 0 2 7 1}$ & 0.0690 \\
TEM_S & $\mathbf{0 . 6 6}$ & 0.12 & 0.23 & $\mathbf{- 0 . 4 4}$ & $\mathbf{0 . 4 1}$ & & $\mathbf{0 . 0 0 0 0}$ \\
TEM_B & $\mathbf{0 . 4 9}$ & 0.01 & 0.22 & -0.29 & 0.33 & $\mathbf{0 . 7 5}$ & \\
\hline
\end{tabular}

randomly selecting a constant number of CPR samples (see Fig. 1). Even if the number of CPR samples in an area remained constant, the use of ships of opportunity by the CPR survey means that inside a geographical box, the spatial distribution of samples varies through time. A biological variable such as diversity can be sensitive to small changes in the mean sampling position. Thus, a biological trend may be a consequence of the sampling trend. The present procedure allows possible links between the long-term changes in both the mean spatial location (latitude and longitude) and the ecosystem indicators to be detected.

Results have shown that it is crucial to control the temporal sampling heterogeneity of the CPR survey and justify the numerical procedure used in this study to build time series. When annual means are used, results show that even the use of a small number of CPR samples $\left(1 \mathrm{mo}^{-1}\right.$, thus $\left.12 \mathrm{yr}^{-1}\right)$ gives satisfactory results (see Figs. 3 \& 4a). However, increasing the number of CPR samples in the estimate also improved the quality of relationships between sea surface 
temperature and the biological environment. When long-term monthly changes are examined, results demonstrate that at least 5 CPR samples should be used (Figs. 3-5, Tables $2 \& 3$ ). The results found in this study are in agreement with those found by Beaugrand \& Edwards (2001). These authors concluded that at least 5 CPR samples were needed to enable reliable spatial and temporal comparisons in the diversity of calanoid copepods to be made. This result also justifies the choice of using a minimum number of 5 neighbours in the spatial interpolation of CPR data by Planque \& Fromentin (1996) and Beaugrand et al. (2000b). Results may not be related to the CPR sampling but to the difficulty of sampling in the pelagic realm. It is unfortunate that such an analysis is only possible with the CPR data, which has extensively monitored the pelagic environment.

\section{Use of species assemblage indicators to monitor responses of marine ecosystems to climate change}

The use of plankton species as indicators of hydroclimatic conditions or water movements has long been stressed (e.g. Russel 1939, Fraser 1955, Glover 1957). For example, the total number of copepods has often been used as a measure of zooplankton abundance (secondary production). It has been previously used by Taylor \& Stephens (1980), Hays et al. (1993), Taylor (1995) to investigate relationships between copepods and the latitudinal position of the Gulf Stream. However, monitoring changes in the marine environment from a single species or taxonomic group may be quite arbitrary, as variable features related to factors such as aggregation or dispersal as well as mortality or survival may influence the distribution of a pelagic organism (Colebrook et al. 1961).

The proposed tool allows the whole calanoid copepod community to be monitored. It uses the total number of species or taxa per CPR sample as an indicator of diversity. This type of indicator is very sensitive to subtle change in ecosystems. For example, it allowed the detection of both the regime shift discovered by Reid et al. (2001) and episodic events described by Edwards et al. (2001) and (2002) in the North Sea (Fig. 6, see also Beaugrand \& Ibañez 2002). The shortcoming of this type of indicator is that it summarises to an extreme (one single value) the structure of an ecosystem. Thus, it may not provide enough information to understand the nature of the observed changes. This is not the case with species-assemblage indicators. The sensitivity and usefulness of species assemblage indicators in the interpretation of changes in the dynamic regime of pelagic ecosystems during episodic events and the regime shift in the North Sea are now demonstrated.

\section{Limitations of the procedure}

The proposed procedure is limited by the sampling coverage of the CPR survey. In some areas under-sampled by the programme (e.g. areas south of $50^{\circ} \mathrm{N}$ in the North Atlantic Ocean), it is possible that the procedure cannot give any estimation of the selected indicators. The use of the method necessitates good knowledge of the geographical distribution of the calanoid copepod species-assemblages and diversity examined in Beaugrand et al. (2000, 2002a,b). The tool should also be applied to individual species in order to examine and quantify which species cause the copepod assemblage or diversity to change in a selected region.

\section{Detection of the regime shift by species assemblage indicators}

Many changes in the biological composition of North Sea marine ecosystems were observed at the end of the 1980s (e.g. Lindley et al. 1990, 1993, Greve 1994). This led Reid et al. (2001) to hypothesise that a regime shift may have occurred in the North Sea. The influence of the regime shift on total calanoid copepod diversity in the central North Sea has been clearly detected in this study. The regime shift has involved a structural reorganisation of marine ecosystems in the central North Sea (Fig. 6). The pronounced decrease in subarctic species, associated with an increase in temperate pseudooceanic species, indicate the move of the central North Sea pelagic ecosystems to a warmer dynamic equilibrium. Also, it denotes a possible link with change along the European shelf-edge as species such as C. helgolandicus (temperate pseudo-oceanic assemblage species) have their centre of spatial distribution along the European shelf edge (Beaugrand et al. 2002b).

\section{Detection of episodic events by species-assemblage indicators}

Edwards et al. (2001, 2002) have recently highlighted the importance of episodic oceanographic events (cold episodic events 1978 to 1982, warm episodic events 1989 to 1991) on the marine ecology of the North Sea. The 2 episodic oceanographic events have clearly been detected in this study. The cold episodic oceanographic event involved profound modifications of the diversity and species composition of ecosystems of the central North Sea (see Fig. 6). It led to a rapid switch in the dynamic regime of the ecosystems, with a stepwise increase in the mean number of subarctic species associated with a reduction in the number of warm-water species. 
The second episodic oceanographic event from the late 1980 s to the early 1990 s was characterised by high salinity anomalies associated with warmer SST (Heath et al. 1991, Becker \& Dooley 1995, Becker \& Pauly 1996, Belkin et al. 1998). This event also impacted North Sea ecosystems. Subarctic species decreased while warm-water pseudo-oceanic and continental shelf species increased, leading to an increase in calanoid copepod diversity.

\section{COMMENTS AND RECOMMENDATIONS}

The study illustrates the importance of providing a unifying framework to monitor the long-term changes in the dynamic regime of marine pelagic ecosystems. It has allowed detection and ecological interpretation of both episodic events and the regime shift in the North Sea. A central recommendation is that the concept of species assemblage indicators could be more widely used to monitor the dynamic regime of pelagic ecosystems. It is rich in information and sensitive. Furthermore, it may lead to a better understanding of the resilience (as defined by Holling 1973) of North Atlantic pelagic ecosystems and, thus, allow future changes to be anticipated.

This study also has important implications for research using the CPR data. Although on the one hand it demonstrates the accuracy of the CPR data, on the other it shows that the spatial and temporal heterogeneity should be carefully assessed before any interpretation of the long-term changes of CPR-derived plankton indicators. This study represents the first attempt to create a time series of any CPR-derived indicator, controlling potential bias related to the spatial and temporal heterogeneity of the CPR sampling. The procedure could be applied to assess the abundance of any taxon monitored by the CPR survey and in any region covered by the programme. The method should also be used to check the sampling intensity of the CPR survey in any region and should also be utilised to cover the North Atlantic Ocean more adequately.

Acknowledgements. I thank Keith Brander for providing ICES data used in this study and for useful comments on the manuscript. I also thank Anthony Richardson for improving the English, and Frederic Ibanez for comments on the research. The author is grateful to all past and present members and supporters of the Sir Alister Hardy Foundation for Ocean Science whose efforts have allowed the long-term establishment and maintenance of the CPR data-set. The survey depends on the owners, masters and crews of the ships that tow the CPRs. This research was supported by the Department for Environment Food and Rural Affairs (DEFRA), the French programme 'Programme National en environnement côtier, thème: influence des facteurs hydroclimatiques ou anthropiques sur la variabilité spatio-temporelle des populations et écosystèmes marins' (PNEC art 4) and the French programme 'Biodiversity and Global Change' from the 'Institut Français de la Biodiversité'.

\section{LITERATURE CITED}

Beaugrand G, Edwards M (2001) Comparison in performance among four indices used to evaluate diversity in pelagic ecosystems. Oceanol Acta 24:467-477

Beaugrand G, Ibañez F (2002) Spatial dependence of pelagic diversity in the North Atlantic Ocean. Mar Ecol Prog Ser 232:197-211

Beaugrand G, Ibañez F, Reid PC (2000a) Long-term and seasonal fluctuations of plankton in relation to hydroclimatic features in the English Channel, Celtic Sea and Bay of Biscay. Mar Ecol Prog Ser 200:93-102

Beaugrand G, Reid PC, Ibañez F, Planque P (2000b) Biodiversity of North Atlantic and North Sea calanoid copepods. Mar Ecol Prog Ser 204:299-303

Beaugrand G, Ibañez F, Lindley JA (2001) Geographical distribution and seasonal and diel changes of the diversity of calanoid copepods in the North Atlantic and North Sea. Mar Ecol Prog Ser 219:189-203

Beaugrand G, Reid PC, Ibañez F, Lindley JA, Edwards M (2002a) Reorganisation of North Atlantic marine copepod biodiversity and climate. Science 296:1692-1694

Beaugrand G, Ibañez F, Lindley JA, Reid PC (2002b) Diversity of calanoid copepods in the North Atlantic and adjacent seas: species associations and biogeography. Mar Ecol Prog Ser 232:179-195

Becker G, Dooley H (1995) The 1989/91 high salinity anomaly. Ocean Challenge 6:52-57

Becker GA, Pauly M (1996) Sea surface temperature changes in the North Sea and their causes. ICES J Mar Sci 53: 887-898

Belkin IM, Levitus S, Antonov J, Malmberg SA (1998) 'Great salinity anomalies' in the North Atlantic. Prog Oceanogr 41:1-68

Botsford LW, Castilla JC, Peterson CH (1997) The management of fisheries and marine ecosystems. Science 277: 509-515

Box GEP, Jenkins GW (1976) Time series analysis: forecasting and control. Holden-Day, San Francisco

Carlton JT, Geller JB (1993) Ecological roulette: the global transport of nonindigenous marine organisms. Science $261: 78-82$

Chatfield C (1989) The analysis of time series: an introduction (4th edn). Chapman and Hall, London

Chatfield C (1996) The analysis of time series: an introduction. Chapman and Hall, London

Chelton DB (1984) Commentary: short-term climatic variability in the northeast Pacific Ocean. In: Pearcy W (ed) The influence of ocean conditions on the production of salmonids in the North Pacific. Oregon State University Press, Corvallis, OR, p 87-99

Colebrook JM (1960) Continuous plankton records: methods of analysis, 1950-59. Bull Mar Ecol 41:51-54

Colebrook JM (1975) The continuous plankton recorder survey: automatic data processing methods. Bull Mar Ecol 8: 123-142

Colebrook JM (1984) Continuous plankton records: relationships between species of phytoplankton and zooplankton in the seasonal cycle. Mar Biol 83:313-323

Colebrook JM, John DE, Brown WW (1961) Contribution towards a plankton atlas of the North-Eastern Atlantic and the North Sea. Part II: Copepoda. Bull Mar Ecol 5:90-97 
Dufrêne M, Legendre P (1997) Species assemblages and indicator species: the need for a flexible asymetrical approach. Ecol Monogr 67:345-366

Edwards M, John AWG, Hunt HG, Lindley JA (1999) Exceptional influx of oceanic species into the North Sea late 1997. J Mar Biol Assoc UK 79:737-739

Edwards M, Reid PC, Planque B (2001) Long-term and regional variability of phytoplankton biomass in the northeast Atlantic (1960-1995). ICES J Mar Sci 58:39-49

Edwards M, Beaugrand G, Reid PC, Rowden AA, Jones MB (2002) Ocean climate anomalies and the ecology of the North Sea. Mar Ecol Prog Ser 239:1-10

Fraser JH (1955) The plankton of the waters approaching the British Isles in 1953. Marine Research Scotland 1:1-12

Fromentin JM, Planque B (1996) Calanus and environment in the eastern North Atlantic. II. Influence of the North Atlantic Oscillation on C. finmarchicus and C. helgolandicus. Mar Ecol Prog Ser 134:111-118

Frontier S, Pichot-Viale D (1993) Ecosystèmes. Structure, fonctionnement, évolution. Masson, Paris

Glover RS (1957) An ecological survey of the Scottish herring fishery. Part II: the planktonic environment of the herring. Bull Mar Ecol 5:1-43

Greve W (1994) The 1989 German Bight invasion of Muggiaea atlantica. ICES J Mar Sci 51:355-358

Hays GC (1994) Mesh selection and filtration efficiency of the continuous plankton recorder. J Plankton Res 16:403-412

Hays GC, Carr MR, Taylor AH (1993) The relationship between Gulf Stream position and copepod abundance from the continuous plankton recorder survey: separating biological signal from sampling noise. J Plankton Res 15: 1359-1373

Heath MR, Henderson EW, Slesser G (1991) High salinity in the North Sea. Nature 352:116

Heath MR, Backhaus JO, Richardson K, McKenzie E and 11 others (1999) Climate fluctuations and the invasion of the North Sea by Calanus finmarchicus. Fish Oceanogr 8 (Suppl 1):163-176

Holling CS (1973) Resilience and stability of ecological systems. Annu Rev Ecol Syst 4:1-23

Hughes L (2000) Biological consequences of global warming: is the signal already apparent? Trends Ecol Evol 15:56-61

Jennings S, Kaiser MJ (1998) The effects of fishing on marine ecosystems. Adv Mar Biol 34:201-352

Lindeboom HJ (1995) Protected areas in the North Sea: an absolute need for future marine research. Helgol Meeresunters 49:591-602

Lindley JA, Reid PC (2002) Variations in the abundance of Centropages typicus and Calanus helgolandicus in the North Sea: deviations from close relationships with temperature. Mar Biol 141:153-165

Lindley JA, Roskell J, Warner AJ, Halliday NC, Hunt HG, John AWG, Jonas TD (1990) Doliolids in the German Bight

Editorial responsibility: Otto Kinne (Editor),

Oldendorf/Luhe, Germany in 1989: evidence for exceptional inflow into the North Sea. J Mar Biol Assoc UK 70:679-682

Lindley JA, Williams R, Hunt HG (1993) Anomalous seasonal cycles of decapod crustacean larvae in the North Sea plankton in an abnormally warm year. J Exp Mar Biol Ecol 173:47-65

Norse EA (1993) Global marine biological diversity. A strategy for building conservation into decision making. Center for marine conservation, Washington

North Sea Task Force (1993) North Sea quality status report. Oslo and Paris Commissions, London

Omori M, Van Der Spoel S, Norman CP (1994) Impact of human activities on pelagic biogeography. Prog Oceanogr $34: 211-219$

Planque B, Fromentin JM (1996) Calanus and environment in the eastern North Atlantic. I. Spatial and temporal patterns of C. finmarchicus and C. helgolandicus. Mar Ecol Prog Ser 134:111-118

Pyper BJ, Peterman RM (1998) Comparison of methods to account for autocorrelation analyses of fish data. Can J Fish Aquat Sci 55:2127-2140

Reid PC, Beaugrand G (2002) Interregional biological responses in the North Atlantic to hydrometeorological forcing. In: Sherman K, Skjoldal HR (eds) Changing states of the large marine ecosystems of the North Atlantic. Elsevier Science, Amsterdam, p 27-48

Reid PC, Hunt HG (1998) Are observed changes in the plankton of the North Atlantic and North Sea linked to climate change? Workshop Rep., Intergovernmental Oceanographic Commission, Amsterdam, 142:310-315

Reid PC, Borges M, Svendsen E (2001) A regime shift in the North Sea circa 1988 linked to changes in the North Sea horse mackerel fishery. Fish Res 50:163-171

Russel FS (1939) Hydrographical and biological conditions in the North Sea as indicated by plankton organisms. J Cons Cons Int Explor Mer 14:171-192

Scheffer M, Carpenter S, Foley JA, Folke C, Walker B (2001) Catastrophic shifts in ecosystems. Nature 413:591-596

Steneck RS (1998) Human influences on coastal ecosystems: does overfishing create trophic cascades? Trends Ecol Evol 13:429-430

Taylor AH (1995) North-South shifts of the Gulf Stream and their climatic connection with the abundance of zooplankton in the UK and its surrounding seas. ICES J Mar Sci 52: 711-721

Taylor AH, Stephens JA (1980) Latitudinal displacements of the Gulf Stream (1966-1977) and their relation to changes in temperature and zooplankton abundance in the NE Atlantic. Oceanol Acta 3:145-149

van der Spoel S (1994) The basis for boundaries in pelagic biogeography. Prog Oceanogr 34:121-133

Warner AJ, Hays GC (1994) Sampling by the continuous plankton recorder survey. Prog Oceanogr 34:237-256

Submitted: June 24, 2003; Accepted: December 2, 2003

Proofs received from author(s): March 8, 2004 